\title{
MOBILIDADE E DESENHO URBANO: Estudo das relações espaciais na cidade de Curitiba
}

\author{
Cristina de Araújo Lima \\ Professora e pesquisadora da Universidade Federal do Paraná (UFPR) \\ cristinadearaujolima@gmail.com \\ Letícia Nerone Gadens \\ Professora e pesquisadora da Universidade Federal do Paraná (UFPR) \\ leticia_gadens@yahoo.com.br
}

\section{RESUMO}

Esse artigo, decorrente de uma pesquisa mais abrangente, tem por objetivo analisar como se apresentam os padrões de desenho urbano nas adjacências de terminais do sistema BRT, considerando que estes equipamentos podem influenciar o seu entorno imediato, evidenciando distintos padrões de ocupação em relação a sua localização na estrutura urbana. Seguindo procedimentos metodológicos de múltiplas técnicas, a análise volta-se à cidade de Curitiba (Brasil) no entorno de terminais localizados na área central, comparativamente àqueles situados em zonas periféricas, considerados vetores de expansão urbana e metropolitana. Os resultados obtidos evidenciam que, embora os terminais periféricos estudados encontrem-se em situações urbanísticas supostamente similares, o padrão de ocupação no seu entorno é distinto, evidenciando lógicas da produção do espaço na escala metropolitana, resultantes da complexidade do fenômeno urbano. O reconhecimento desses padrões no entorno de equipamentos de uso intensivo pode contribuir com o planejamento e gestão pública, otimizando recursos e a qualidade espacial.

Palavras-chave: Desenho urbano, mobilidade, terminais de transporte, transit-oriented development.

\begin{abstract}
This article, based on a more comprehensive research, aims to analyze how urban design patterns are presented in the environs of BRT terminals, considering that these equipments can influence their immediate surroundings, evidencing different occupancy patterns in relation to their urban structure. Following methodological procedures of multiple techniques, the analysis is done in the city of Curitiba (Brazil) nearby terminals located in the central area, compared to those located in peripheral zones, considered vectors of urban and metropolitan expansion. The results show that, although the peripheral terminals studied are located in supposedly similar urban situations, the pattern of occupation close by these terminals is distinct, evidencing logics of space production in the metropolitan scale, resulting from the complexity of the urban phenomenon. The recognition of these standards in the environment of intensive equipment can contribute to public planning and management, optimizing resources and spatial quality.
\end{abstract}

Keywords: Urban design, mobility, transport terminals, transit-oriented development. 


\section{INTRODUÇÃO}

Este trabalho decorre de um contexto mais abrangente, em parceria com grupos de pesquisa da França e EUA intitulado Ignis Mutat Res, em desenvolvimento no Grupo Cidade, Meio Ambiente e Políticas Públicas (CIMAPP), do Departamento de Arquitetura e Urbanismo da Universidade Federal do Paraná. Assim, o presente recorte investigativo foi proposto a partir de uma perspectiva de análise da relação estabelecida entre o desenho urbano e os espaços utilizados pelos sistemas de mobilidade, especialmente o sistema BRT (bus rapid transport), uma proposta criada em Curitiba na década de 1970.

Nesse contexto, parte-se da premissa de que a concentração de pessoas e atividades diversificadas no entorno de serviços de transporte permite a convergência de demandas, maximizando a eficiência do sistema de transporte coletivo e reduzindo a necessidade de deslocamentos motorizados, em consonância com o conceito de desenvolvimento orientado do transporte público - transit-oriented development - TOD (Newman, 1996; Lund, Cervero, Wilson, 2004; Petersen, 2004; Jabareen, 2006; Litman, 2008).

Por outro lado, a própria existência da oferta de serviços de transporte público também atua como um indutor de desenvolvimento urbano na medida em que torna a ocupação de áreas próximas atrativas, pela facilidade de acesso ao serviço. Litman (2008) argumenta que as estratégias de desenho urbano baseadas no conceito de desenvolvimento orientado do transporte público (TOD) podem aumentar de duas a cinco vezes a quantidade de passageiros, além de reduzir entre $8 \%$ a $32 \%$ o número de viagens em automóveis.

Assim, a pesquisa se apresenta em um contexto que discute a conformação do espaço urbano como produto social desenrolado historicamente (Harvey, 2010) no qual o desenho intervém como projeto (Del Rio, 1990; Lamas, 2014; Del Rio, Siembieda, 2015). Na perspectiva do artigo, o projeto urbano se alinha com práticas de sustentabilidade, considerando os argumentos em favor de uma cidade compacta, organizada a partir de diversidade de usos, espaços que favoreçam deslocamentos a pé e que se articulem com diversos modais de transporte. Portanto, considera-se que a inclusão do sistema do transporte coletivo é fundamental neste processo, sendo esta prática, inclusive, disseminada globalmente (Kenworthy, Laube,1999; Kates, Parris, Leiserowitz, 2005; Palomo, 2005; Amado, 2009; Freyman, 2012). Na direção de um urbanismo mais sustentável, se entende que as densidades urbanas podem ser otimizadas em relação à presença de infraestrutura, equipamentos e serviços, o que pode ser fortalecido pelos usos mistos, que além de contribuírem para menor necessidade de deslocamentos, tornam os lugares mais completos quanto à oferta de atividades (Charlot-Valdieu, Outrequin, 2011; Masboungi, 2012).

A discussão proposta reconhece que a forma urbana (Pereira Costa; Teixeira, 2014) é influenciada diretamente pelas conexões possibilitadas pelo sistema de transporte público, ao passo que, quanto mais eficientes tais conexões maiores as possibilidades de deslocamento e conectividade entre pessoas e atividades (Salingaros,1998). Portanto, esta pesquisa tem por objetivo central analisar como se apresentam os padrões de desenho urbano focalizando o entorno de terminais do sistema BRT, do ponto de vista físicoespacial, considerando que estes equipamentos podem influenciar o seu entorno imediato (especialmente os usos que funcionam como pólos geradores de tráfego, que podem concentrar usos diminuindo trânsito, no sentido proposto por Beatley (2000), evidenciando padrões de ocupação que reproduzem distintos comportamentos em relação a sua localização na estrutura urbana (conjunto de sistemas de infraestrutura, equipamentos e serviços sobre a base físico-material).

Seguindo o recorte metodológico e propositivo da pesquisa (Marconi, Lakatos, 2004), o estudo foi aplicado na cidade de Curitiba, a partir de uma análise dos padrões de ocupação no entorno de terminais localizados na área central comparativamente àqueles localizados nas áreas periféricas, próximas aos municípios que apresentam os maiores índices de crescimento populacional e consistem, portanto, em áreas de expansão urbana e metropolitana. Tal escolha justifica-se pelo fato de que tais terminais, localizados nos chamados "eixos estruturais", podem evidenciar formas de desenho urbano que refletem lógicas de urbanização não apenas de Curitiba, mas também de seus municípios vizinhos, tendo em vista que tais eixos atuam como vetores de expansão urbana e possibilitam conexões metropolitanas.

\section{O DESENHO URBANO DE CURITIBA A PARTIR DOS EIXOS ESTRUTURAIS}

Curitiba é polo de uma região metropolitana formada por 29 municípios, sendo que destes, 14 integram o chamado Núcleo Urbano Central (NUC), constituído por aqueles municípios que compõem uma mancha urbana contínua, com padrão de ocupação semelhante e que concentram a dinâmica regional mais intensa 
(COMEC, 2006). A cidade é reconhecida internacionalmente por suas práticas de urbanismo, sobretudo pela utilização de um modelo de ocupação urbana fundamentado na relação entre uso do solo, sistema viário e transporte coletivo. Essa concepção possibilitou a implantação do BRT, um sistema inovador que foi reinterpretado em diversos municípios no Brasil, além de outros países (IPPUC, 2016). Este exemplo de inovação esteve alinhado a valores de desenvolvimento sustentável, capacidade de deslocamento, baixo custo, sendo, portanto, solução aplicável em países desenvolvidos ou em desenvolvimento (Allaire, 2006).

Esta abordagem foi inserida a partir do Plano Preliminar de Urbanismo proposto em 1965, quando se adotou um modelo linear de expansão urbana com o objetivo de orientar o processo de crescimento da cidade de forma ordenada, a partir da integração das funções do sistema viário, transporte coletivo e uso do solo (IPPUC, 2004). A partir de então, o desenho urbano de Curitiba evidencia o aspecto conceitual desta proposta, ao prever maior densidade de ocupação ao longo dos eixos estruturais da cidade, os quais comportam o espaço destinado a circulação do sistema BRT (Figura 01). Contudo, conforme Campos (2005), visando a rápida consolidação destes setores da cidade, o processo de ocupação se deu por incentivos oferecidos por meio de diversas alterações na legislação vigente, configurando espaços de alta densidade, com edifícios sem qualquer afastamento das divisas. Como consequência, surgiram sérios problemas bioclimáticos, como o sombreamento excessivo causado pela proximidade das edificações verticalizadas em uma estrutura fundiária antiga, planejada para comportar baixas densidades.

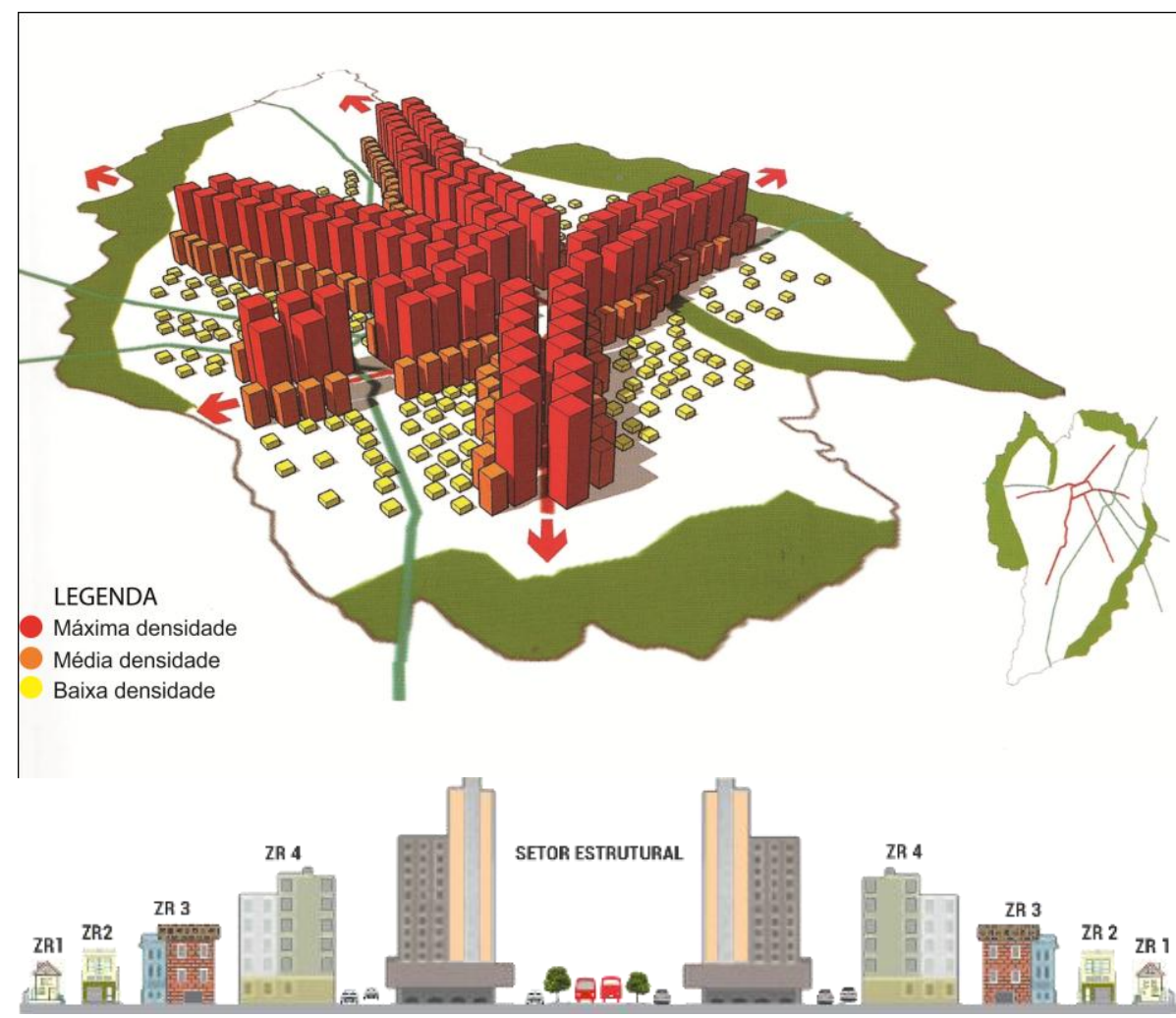

Figura 01: Eixos estruturais propostos no Plano Preliminar de Urbanismo (1965) - perspectiva aérea e corte esquemático (Dudeque, 2010; URBS, 2016)

Assim, os eixos estruturais, desenhados de forma tentacular, foram pensados para distribuir o acesso ao transporte coletivo nas diferentes áreas da cidade, facilitando seu uso (IPPUC, 2004). Em tese, esta seria uma proposta de ocupação urbana na qual o sistema BRT seria utilizado pelos moradores dos eixos estruturais, resultando em concentração da demanda, facilidade de acesso ao transporte coletivo e, consequentemente, melhor eficiência do sistema como um todo. No entanto, esta concepção, alinhada ao conceito de desenvolvimento orientado do transporte público (TOD), não reflete a realidade atual desta estrutura urbana, ao se pressupor que os usuários do transporte coletivo não habitam os eixos estruturais, destinados ao sistema BRT, o que seria mais sustentável (Lima, Fortunato, 2016).

Esse processo também foi resultado da conformação do mercado de terras, onde se observa que houve uma grande valorização econômica dos imóveis localizados nos eixos estruturais, provocando exclusão social e o espraiamento da mancha urbana em direção aos municípios vizinhos. Consequentemente, o processo de ocupação urbana, sobretudo nas décadas de 1970 e 1980, transpôs as fronteiras 
administrativas de Curitiba, criando áreas contíguas de ocupação nos municípios limítrofes (COMEC, 2006). Esse avanço da ocupação, além de acarretar crescimento das demandas por infraestrutura, equipamentos e serviços, também representa risco aos mananciais de abastecimento público, situados nos municípios da região metropolitana (Lima, 2000).

Segundo dados do último censo demográfico, Curitiba possui 1.751.907 habitantes (IBGE, 2010), que corresponde à $54,34 \%$ da população metropolitana, equivalente à 3.223 .836 , no total. Considerando o contexto metropolitano, Curitiba apresenta a segunda menor taxa de crescimento geométrico populacional $(0,99 \%)$ comparativamente aos municípios que integram o NUC, evidenciando que o crescimento da região está ocorrendo, de forma significativa, em alguns municípios do Núcleo Urbano Central, principalmente naqueles situados na porção sudeste-sul (Tabela 01).

\begin{tabular}{|l|c|c|c|}
\hline Município & $\begin{array}{l}\text { Densidade demográfica } \\
\text { (hab. } / \mathbf{k m}^{2} \text { ) }\end{array}$ & Grau de urbanização (\%) & $\begin{array}{l}\text { Taxa de crescimento } \\
\text { geométrico populacional } \\
\text { segundo tipo de domicílio } \\
\text { (\%) }\end{array}$ \\
\hline Almirante Tamandaré & 597,18 & 95,82 & 1,57 \\
\hline Araucária & 287,39 & 92,51 & 2,37 \\
\hline Campina Grande do Sul & 78,03 & 82,44 & 1,15 \\
\hline Campo Largo & 98,02 & 83,80 & 1,93 \\
\hline Campo Magro & 100,22 & 78,68 & 1,51 \\
\hline Colombo & 1187,74 & 95,42 & 0,99 \\
\hline Curitiba & 4349,07 & 100,00 & 2,65 \\
\hline Fazenda Rio Grande & 812,38 & 92,96 & 2,13 \\
\hline Itaperuçu & 84,74 & 83,54 & 1,28 \\
\hline Pinhais & 2097,85 & 100,00 & 2,49 \\
\hline Piraquara & 471,23 & 49,07 & 2,08 \\
\hline Quatro Barras & 123,32 & 90,38 & 0,44 \\
\hline Rio Branco do Sul & 39,63 & 71,92 & 2,60 \\
\hline São José dos Pinhais & 320,62 & 89,66 & $\mathbf{1 , 3 7}$ \\
\hline RMC & $\mathbf{2 1 2 , 7 8}$ & $\mathbf{9 1 , 7}$ & \\
\hline
\end{tabular}

Tabela 01: Dados populacionais dos municípios que integram o NUC - Região Metropolitana de Curitiba (IPARDES, 2016; IBGE, 2010)

Esta já era uma tendência verificada no Plano de Desenvolvimento Integrado, elaborado para a Região Metropolitana de Curitiba, em 2006, quando foram previstos vetores de expansão urbana, cujas projeções indicavam que mais da metade do acréscimo de população prevista para os municípios integrantes do NUC ocorreria no arco leste metropolitano (58,22\%), ou seja, nos municípios de Colombo, Campina Grande do Sul, Quatro Barras, Pinhais, Piraquara e São José dos Pinhais (Figura 02). Destaca-se ainda que, considerando os municípios ao sul-sudoeste de Curitiba, ou seja, Fazenda Rio Grande e Araucária, essa participação corresponderia à $77,84 \%$ (COMEC, 2006).

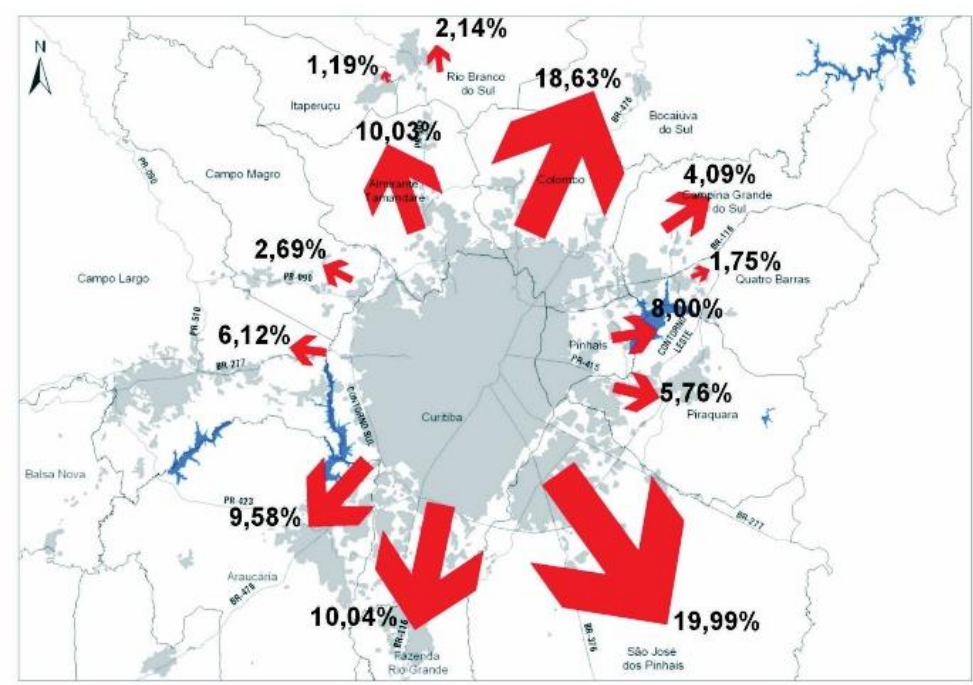

Figura 02: Vetores de expansão / percentual de acréscimo populacional 2000 - 2020 do NUC (COMEC, 2006) 
Assim, o recorte adotado para esta pesquisa concentrou-se em um estudo comparativo dos padrões de ocupação urbana no entorno dos terminais do sistema BRT localizados na área central de Curitiba e nos eixos estruturais do anel periférico sudeste e sul, conforme demonstra o quadro abaixo.

\begin{tabular}{|l|l|l|}
\hline \multicolumn{1}{|c|}{$\begin{array}{c}\text { Terminais de } \\
\text { transporte coletivo }\end{array}$} & \multicolumn{1}{|c|}{ Eixo estrutural } & \multicolumn{1}{c|}{$\begin{array}{c}\text { Município metropolitano } \\
\text { mais próximo }\end{array}$} \\
\hline Praça Tiradentes & Área central de Curitiba & - \\
\hline Praça Rui Barbosa & Área central de Curitiba & - \\
\hline Terminal Capão Raso & Eixo estrutural sul & Fazenda Rio Grande \\
\hline Terminal Boqueirão & Eixo estrutural sudeste (Eixo Boqueirão) & São José dos Pinhais \\
\hline
\end{tabular}

Quadro 01: Recorte espacial de análise

Elaboração própria considerando dados da Tabela 01

Em Curitiba, no ano de 2015 foram transportados 1.619 .647 passageiros (URBS, 2016). O sistema BRT é formado por $72 \mathrm{~km}$ de canaletas exclusivas para ônibus em Curitiba que conectam os 29 terminais da cidade, além de 14 terminais localizados nos 13 municípios vizinhos que integram a Rede Integrada de Transporte RIT (IPPUC, 2016). Assim, visando a verificação do objetivo central desta pesquisa, foram aplicados procedimentos metodológicos para análise dos quatro terminais elencados para o estudo, os quais são sintetizados a seguir. Posteriormente, são apresentadas as análises e os resultados obtidos, encerrando com as considerações finais referentes ao tema aqui proposto.

\section{CONSIDERAÇÕES METODOLÓGICAS}

A metodologia utilizada para o desenvolvimento da pesquisa corresponde ao método hipotético-dedutivo, que consiste em identificar os problemas existentes, entre as expectativas e as possíveis teorias onde serão testados, para encontrar soluções mais plausíveis da realidade (Popper, 1975). Considerou-se também a aplicação do método comparativo, permitindo a análise por elementos determinados de forma original em relação ao espaço urbano (Marconi, Lakatos, 2004). Ressalta-se que para este artigo foram aplicados os procedimentos metodológicos considerando quatro terminais de análise. No entanto, a pesquisa em seu todo contempla um recorte analítico mais abrangente composto por 21 terminais que integram o sistema BRT na cidade de Curitiba e Região Metropolitana, do universo de 33 situados no Núcleo Urbano Central.

Os critérios de análise foram aplicados na área adjacente dos quatro terminais selecionados, considerando o recorte espacial no entorno imediato destes equipamentos. A definição deste recorte tomou por base o raio de abrangência de 500 metros, definido a partir da localização do terminal em análise. Essa distância é adotada pelo Instituto de Pesquisa e Planejamento Urbano de Curitiba (IPPUC), a partir da observação de práticas dos moradores e consta na Lei Municipal n. $\cong 12.597 / 2008$, que dispõe sobre a organização do sistema de transporte coletivo da cidade. Em seu artigo 4ํㅡ a referida lei define que determinada região será considerada atendida pelo sistema de transporte sempre que sua população não esteja sujeita à deslocamentos médios superiores à 500 metros. Esta distância também é equivalente à relação de tempo de deslocamento entre paradas de ônibus, desenvolvida por Silveira (2012), com base em Alter (1976).

Para aplicação dos critérios de análise foram considerados quatro recortes espaciais. Destes, dois encontram-se no centro da cidade de Curitiba - Tiradentes e Rui Barbosa e, portanto, apresentam ocupação urbana mais antiga e consolidada. Estes dois recortes configuram-se como praças as quais, em razão da significativa oferta de linhas de transporte coletivo, são considerados terminais urbanos. A Praça Rui Barbosa funciona como terminal desde o início da implantação do Sistema BRT, em 1974. A Praça Tiradentes corresponde ao local de criação política de Curitiba e, portanto, seu marco zero, a partir da onde se tomam todas as distâncias da cidade. O Terminal Capão Raso é um terminal pioneiro no sistema BRT, tendo sido implantado em 1974 (PMC, 2016). Encontra-se no vetor sul de Curitiba, estabelecendo conexão com o município de Fazenda Rio Grande, o qual possui a maior taxa de crescimento geométrico do NUC, 2,65\% (IBGE, 2010). Já o Terminal do Boqueirão, atende ao fluxo do eixo implantado em 1977 (PMC, 2016), situado na porção sudeste de Curitiba, região que permite a conexão da cidade com a Região Metropolitana, especialmente com o município de São José dos Pinhais, o qual apresenta a segunda maior taxa de crescimento geométrico populacional, correspondente à 2,60\% (IBGE, 2010). 


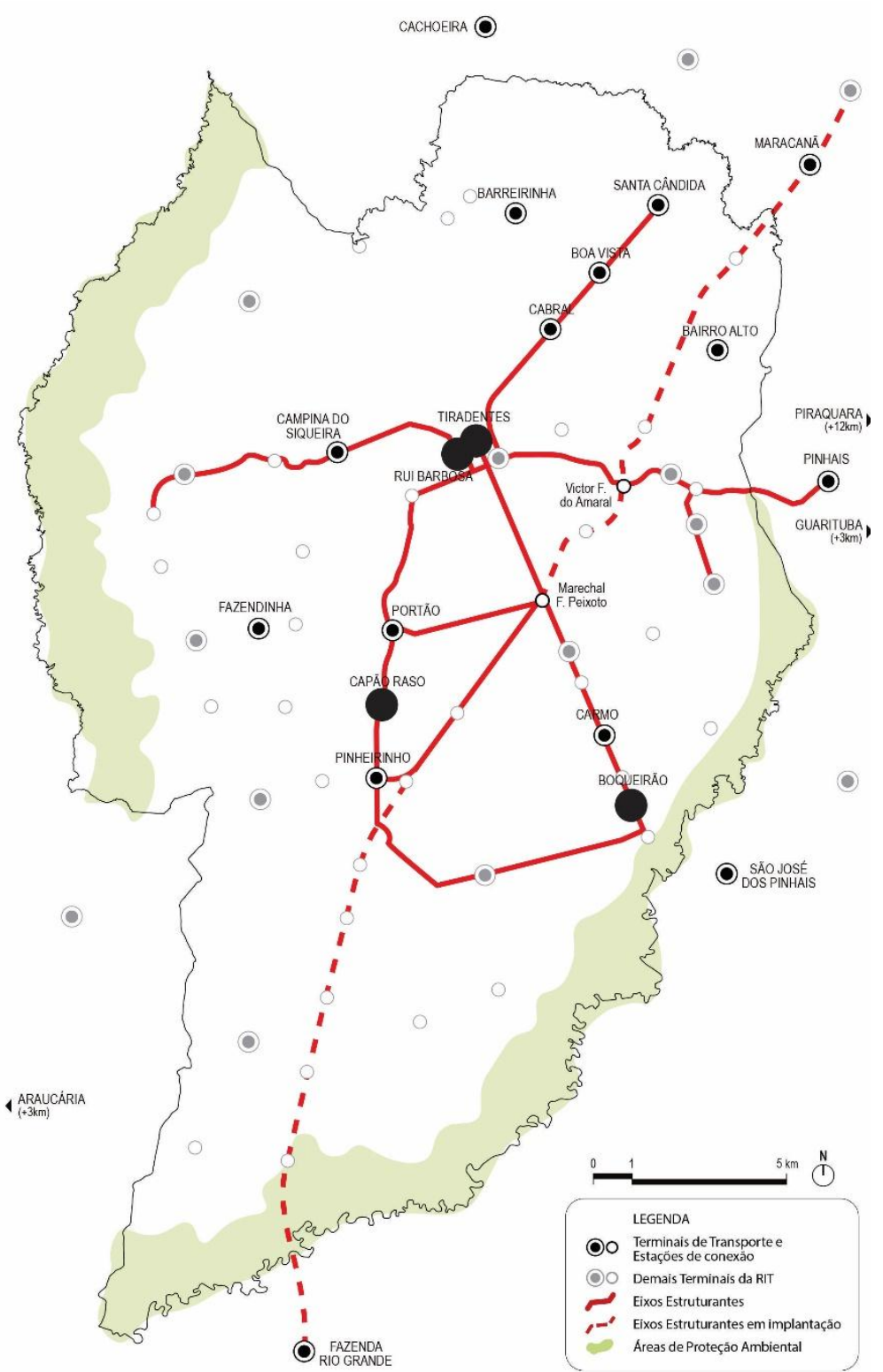

Figura 03: Eixos estruturais de Curitiba e terminais urbanos, com destaque para os terminais analisados Elaborado com base em URBS, 2016

Os recortes periféricos apresentam, em seus respectivos bairros, a predominância de população com rendimento nominal mensal de até 3 salários mínimos, similar ao perfil da cidade de Curitiba. Apenas no bairro Centro, onde localizam-se a Praça Tiradentes e Rui Barbosa é que se observa a inversão deste quadro, com predominância de população com rendimento nominal mensal acima de 3 salários mínimos (Quadro 02).

\begin{tabular}{|l|c|c|}
\hline \multicolumn{1}{|c|}{ Recorte espacial } & $\mathbf{0 - 3}$ salários mínimos & Acima de 3 salários mínimos \\
\hline Centro & $40 \%$ & $60 \%$ \\
\hline Capão Raso & $65 \%$ & $35 \%$ \\
\hline Boqueirão & $54 \%$ & $46 \%$ \\
\hline Curitiba & $\mathbf{6 0 \%}$ & $\mathbf{4 0} \%$ \\
\hline
\end{tabular}

Quadro 02: Rendimento nominal mensal segundo os bairros de Curitiba

(IBGE, 2010)

No eixo estrutural sul, a jusante do Terminal Capão Raso, ainda se encontra o último terminal localizado em Curitiba, denominado Pinheirinho. No entanto, para esta pesquisa, optou-se pela adoção do recorte espacial do Terminal Capão Raso em virtude de que o mesmo se encontra à distância intermediária em relação ao centro da cidade, de forma similar comparativamente ao Terminal do Boqueirão, o que permitiria identificar, gradualmente, em relação ao centro e nos eixos dos vetores de crescimento populacional, quais padrões de ocupação se observam, a partir dos critérios de análise. Assim, a escolha dos recortes espaciais adotados 
para análise justifica-se em razão da possibilidade de se estabelecer comparativos entre padrões urbanos que ocorrem no centro e nos eixos periféricos onde concentram-se os principais vetores de crescimento do Núcleo Urbano Central da Região Metropolitana de Curitiba.

Visando atender ao objetivo central da pesquisa, foram aplicados sobre esses recortes espaciais, os critérios de análise de zoneamento, que correspondem à categoria 1 e tem por objetivo verificar a previsão legal de uso e ocupação do solo para o local, tendo em vista que a normativa no entorno de cada terminal analisado é distinta ao estabelecer diferentes parâmetros de zoneamento. A categoria 2 objetiva, a partir da coleta de informações in loco, identificar a distribuição de usos nos lotes existentes no recorte analisado, demonstrando padrões de diversidade. Além disso, foram verificados padrões de densidade populacional nos recortes de análise, comparativamente à média de Curitiba, buscando evidenciar relações de maior ou menor concentração de pessoas em função da existência do terminal urbano (categoria 3). Por fim, na categoria 4 foram identificados e analisados os dados de circulação de ônibus e existência de polos geradores de tráfego a fim de estabelecer relações entre fluxos do sistema de transporte coletivo e a ocupação urbana do seu entorno.

Por meio da aplicação dos critérios, foi realizada uma análise quantitativa, estabelecendo-se escala de valores por meio da aplicação de referências teóricas que embasaram a definição de tais critérios (Kohlsdorf, 1996; Lima, 2010; Lima, 2015). Os critérios de análise e a respectiva escala de valores estabelecida são apresentados no Quadro 03. Atribui-se aos critérios que se referem às condições sócio espaciais o total de 66 pontos (categorias 1 à 3 ) e à categoria 4 , que analisa à oferta de transporte e existência de polo geradores de tráfego a valoração de 34 pontos, considerando o pressuposto de que esta categoria é relevante na conformação das demais, em termos de uso e ocupação do espaço.

\begin{tabular}{|l|l|c|}
\hline \multicolumn{1}{|c|}{ Categorias } & \multicolumn{1}{|c|}{ Critérios de análise } & \multicolumn{1}{c|}{ Escala de valores } \\
\hline Categoria 1 & Zona & 28 pontos \\
\hline Categoria 2 & Diversidade de usos & 28 pontos \\
\hline Categoria 3 & Densidade populacional & 34 pontos \\
\hline Categoria 4 & $\begin{array}{l}\text { Circulação de ônibus } \\
\text { Polo gerador de tráfego }\end{array}$ & 100 pontos \\
\hline \multicolumn{2}{|l|}{ Total }
\end{tabular}

\section{Quadro 03: Escala de valores dos critérios de análise}

Elaboração própria

Cada categoria de análise é formada por uma série de critérios provenientes de leitura espacial, totalizando 11 itens observados in loco (Tabela 02). A partir destas informações foram elaboradas peças gráficas que representam o recorte espacial em planta, elevação e perspectiva, por meio do uso do software SketchUp, de modo a representar a conformação dos espaços de análise. Os dados também foram organizados de forma tabular e analisados comparativamente por meio de gráficos. Adotou-se como pressuposto de análise a consideração de que as intervenções que implantaram os terminais urbanos responderam inicialmente às necessidades do sistema de mobilidade. Posteriormente, os terminais passaram a atuar como subcentros, ou pontos nodais, criando entornos próprios, que consiste no objeto de análise desta pesquisa. A seguir são apresentados os resultados obtidos a partir da aplicação dos procedimentos metodológicos.

\section{ANÁLISE DOS RESULTADOS}

Com o objetivo de responder à questão central da pesquisa, que consiste em analisar como se apresenta o desenho urbano no entorno dos terminais que compõem o sistema BRT, estabelecendo comparativos entre àqueles situados na área central e na periferia de eixos estruturais que conectam à municípios com maiores taxas de crescimento populacional, foram aplicados os critérios de análise. Estes parâmetros consideraram a avaliação da diversidade de usos e densidade de ocupação em relação à caracterização do terminal de transporte coletivo, enquanto subcentro capaz de gerar uma dinâmica específica no seu entorno. 0 resultado síntese dos dados coletados, bem como a repercussão espacial dos mesmos são apresentados no Quadro 04. 

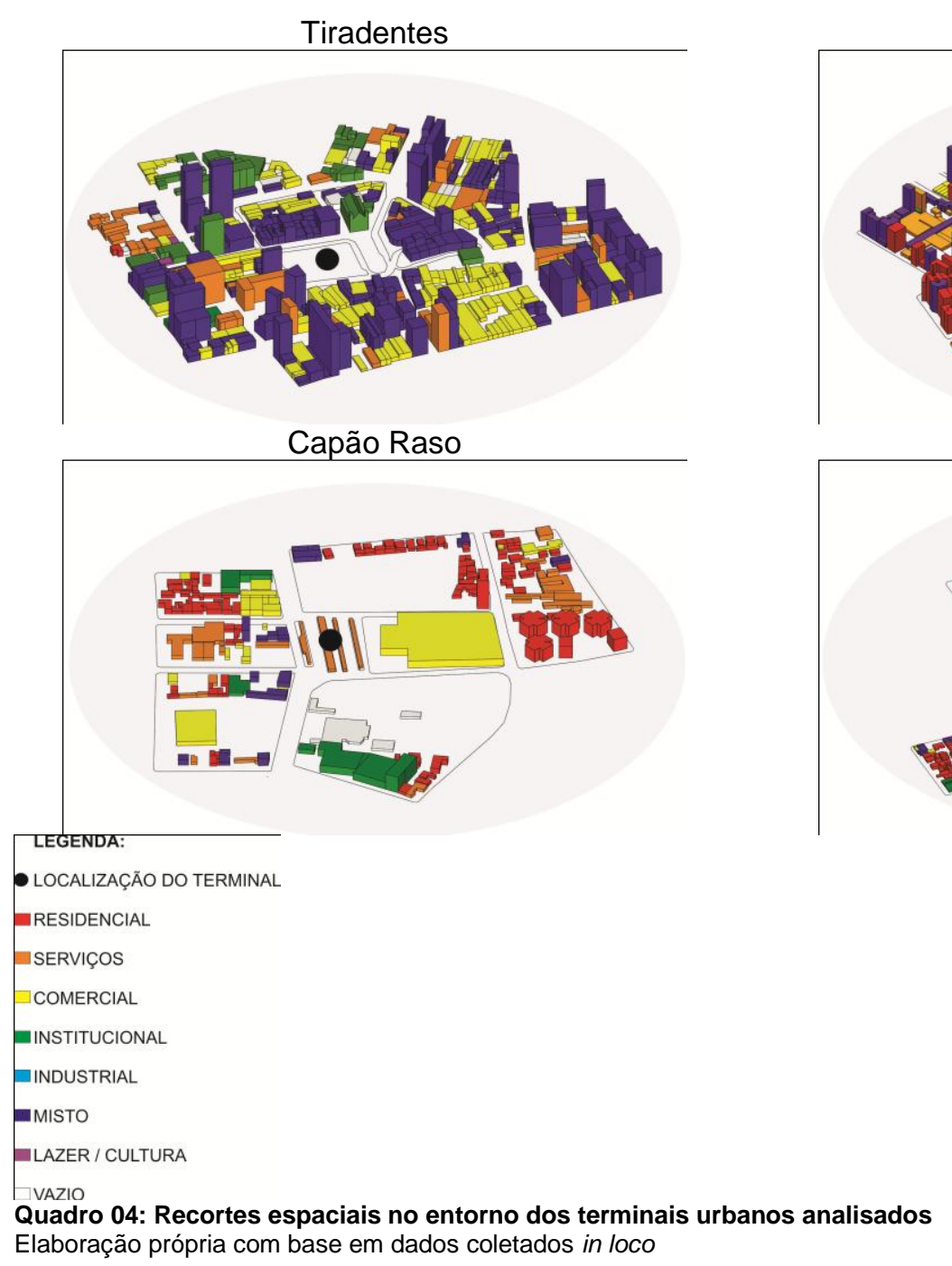

Com base na reprodução espacial dos recortes de estudo é possível identificar que há contrastes significativos na ocupação do entorno dos terminais analisados, tendo em vista que nas áreas centrais (Tiradentes e Rui Barbosa) a estrutura fundiária é formada por lotes de menores dimensões o que contribui, entre outras questões, para a maior verticalização da ocupação, conformando uma estrutura urbana mais densa e compacta. A despeito disso, verifica-se ainda que os usos mistos, comercial e de serviços correspondem aos mais expressivos na área central, representando $88 \%$ e $77,81 \%$ das edificações existentes no recorte analisado na Praça Tiradentes e Rui Barbosa, respectivamente. No entanto, o uso de comércio e serviços é mais relevante no entorno da Praça Tiradentes (51,6\% das edificações), enquanto que nas imediações da Praça Rui Barbosa predominam comércio e serviços associados à habitação, equivalendo à $41,78 \%$ das edificações com uso misto. Esse resultado evidencia significativa diversidade de usos, considerando que o uso misto tem um componente residencial.

Observando essa mesma tipologia de usos nos recortes dos entornos dos Terminais do Capão Raso e Boqueirão, verifica-se menor expressividade de usos que associem comércio e serviços com habitação (aproximadamente 9\% das edificações). Verifica-se ainda que o recorte de análise do Terminal do Capão Raso apresenta ocupação predominantemente residencial (61\%), demonstrando um padrão de ocupação que diverge do estudo das imediações do Terminal do Boqueirão, que apresenta proporção de uso residencial em torno de $40 \%$, equivalente a soma da proporção de atividades de comércio e serviços. A despeito de outras questões que possam influenciar nesse padrão de ocupação, verifica-se com base nesta amostra que, embora trate-se do mesmo equipamento público (terminal de transporte), sua influência no padrão de ocupação do entorno imediato é bastante divergente, considerando a análise de terminais em situações periféricas e, supostamente, similares (Gráfico 01). 


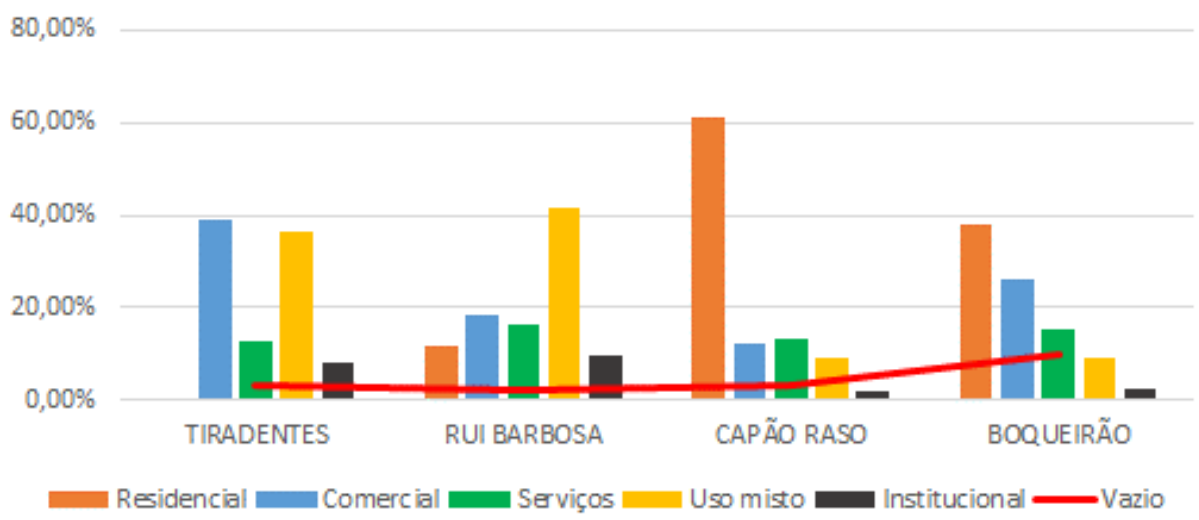

Gráfico 01: Distribuição de usos por recorte espacial analisado Elaboração com base na coleta de dados in loco

Considerando o Quadro 04, se verifica expressiva diferença entre a densidade construtiva e distribuição de usos. Nas áreas centrais há o predomínio do uso misto e construções com maior número de pavimentos. Nos Terminais Capão Raso e Boqueirão, que correspondem aos recortes periféricos, há divergência na distribuição de usos, bem como na densidade construtiva. Nestes terminais, considerando também as informações do Gráfico 01, se verifica que predomina o uso residencial, enquanto o uso misto que agrega o uso residencial a comércio ou serviços, é pouco representativo. Além do uso residencial ser predominante nos recortes periféricos, ele é caracterizado principalmente pela habitação unifamiliar, sendo uma edificação de uso exclusivo no lote. No caso específico do Terminal do Boqueirão, verifica-se que a densidade construtiva geral (que congrega todos os diversos usos) apesar de alta, comparativamente com o outro terminal periférico, não resulta em alta densidade populacional, conforme demonstrado no Gráfico 02 . Este fato pode ser decorrente do uso residencial de habitações unifamiliares ocorrer em padrão de baixa densidade.

A pesquisa propiciou também reflexão acerca da relação entre as condições de densidade de ocupação nos diferentes terminais, a centralidade de equipamentos e modos de transporte pelo sistema BRT. A centralidade foi compreendida pela disponibilidade da infraestrutura ou equipamentos e por sua localização, levando em conta a diversidade do espaço público (FRÚGOLI JUNIOR, 1995; ARRAIS, 2005) e considerando que o território não é apenas o locus da produção, mas objeto de consumo (VARGAS, CASTILHO, 2006). No recorte analisado, observou-se que, além da distinta distribuição de usos existente mesmo quando comparados os entornos dos terminais localizados no extremo periférico de análise, há também distintas densidades populacionais. No entanto, considerando a amostra analisada, com exceção do entorno do Terminal do Boqueirão, as demais apresentam densidades populacionais superiores à média de Curitiba (43,54 hab./ha). O Gráfico 02 demonstra os resultados obtidos nesta categoria de análise, evidenciando que o recorte da Praça Rui Barbosa e Capão Raso apresentam densidades populacionais próximas, o que poderia ser evidencia de conformação de uma nova centralidade no entorno deste último terminal, distante do marco zero. 


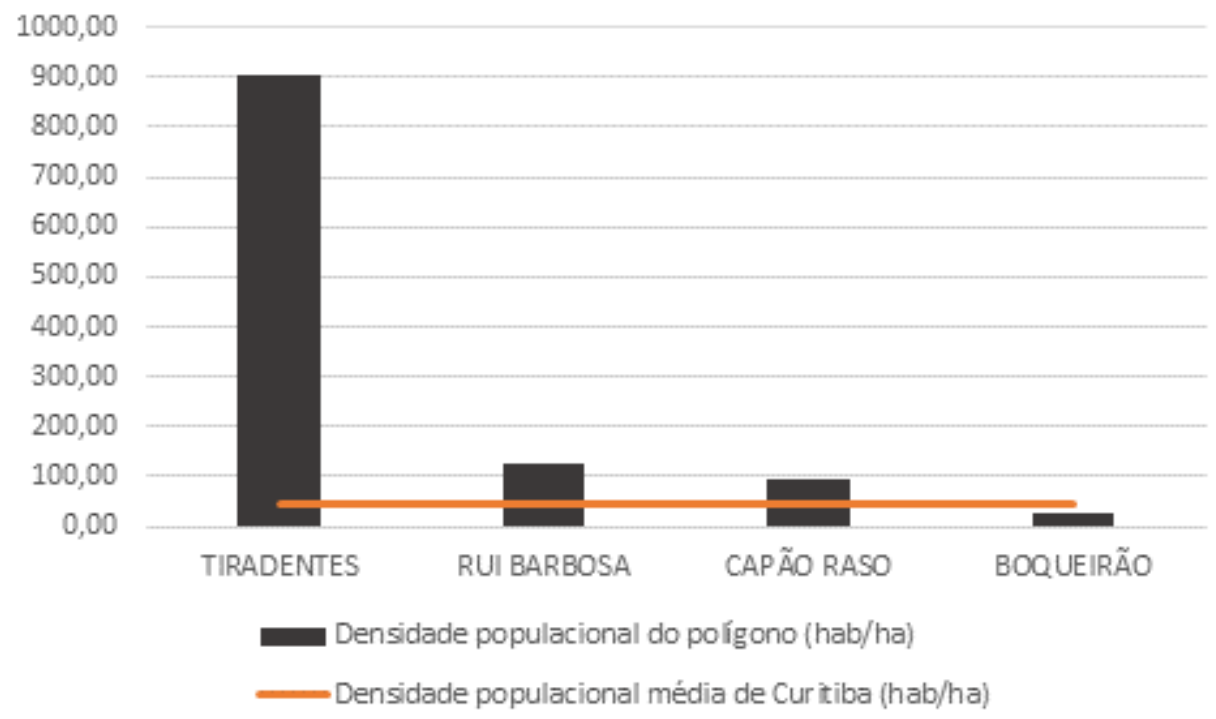

Gráfico 02: Densidade populacional por recorte espacial analisado e densidade média de Curitiba (IBGE, 2010)

Tendo em vista os dados do Gráfico 03, e estabelecendo um comparativo com as demais categorias de análise, verifica-se ainda que a densidade populacional não está diretamente relacionada à predominância de usos residenciais nos recortes de análise. Esta condição pode evidenciar que a estrutura fundiária tem um papel relevante nesta conformação, ao identificar maiores densidades na área central, onde há o predomínio de uma ocupação verticalizada em lotes menores do que os existentes no recorte periférico. Além disso, embora exista diferenciação na oferta de linhas de ônibus, que é mais expressiva nos recortes das Praças Tiradentes e Rui Barbosa, verifica-se que não há relação direta entre densidade populacional e oferta do transporte (Gráfico 04). Este resultado pode denotar que o sistema de transporte se encontra deficitário em áreas que tem apresentado recente crescimento, como as áreas periféricas do sudeste de Curitiba, ou estão saturadas em locais de alta densidade populacional, como os recortes centrais da pesquisa (Terminais Tiradentes e Rui Barbosa). Este resultado ainda sinaliza uma possibilidade a ser averiguada na sequência da pesquisa, de que o uso do automóvel particular ao suprir o déficit de transporte nas áreas periféricas, poderia interferir na relação entre oferta de transporte coletivo e densidades populacionais.

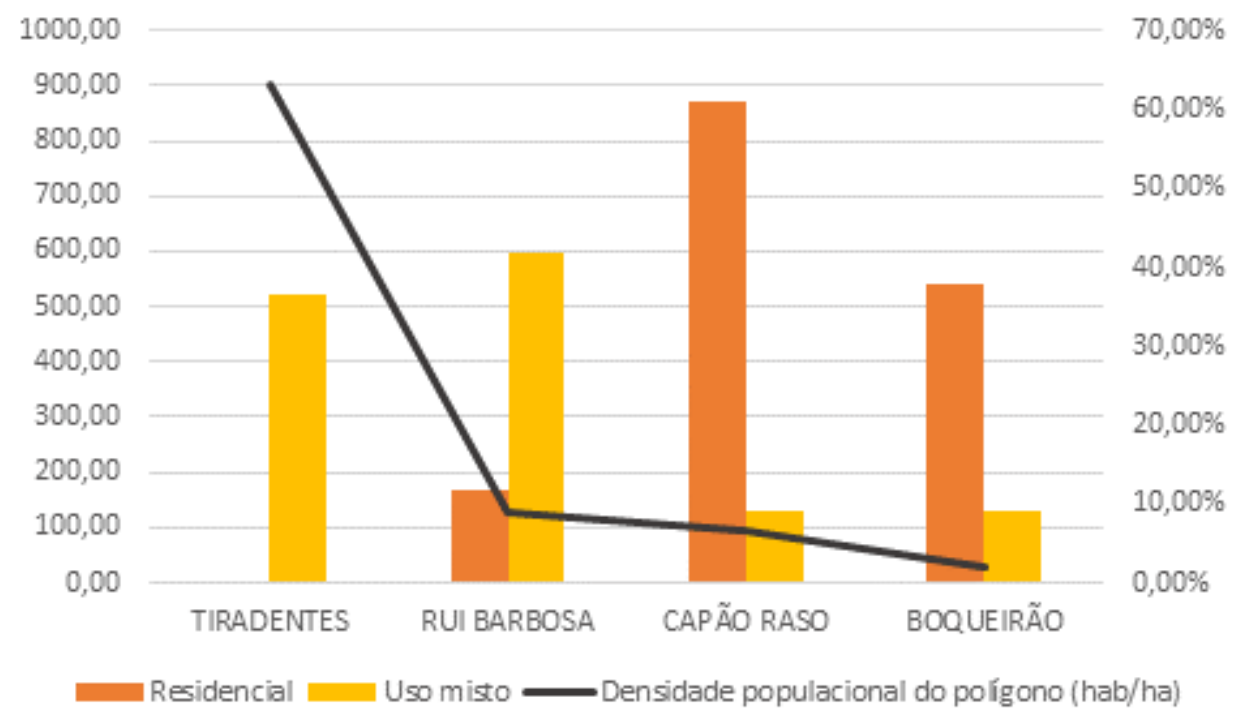

Gráfico 03: Densidade populacional e distribuição de usos residencial e misto por recorte espacial analisado (IBGE, 2010; verificação in loco, 2016)

O Gráfico 04 apresenta dados relativos ao número de linhas de ônibus ofertadas e o número de ônibus circulantes nos horários de pico matutino e vespertino. Iniciando pelo total de linhas de ônibus, se verifica que nos terminais centrais existe uma maior quantidade de oferta, com média de 53 linhas em operação. 
Por outro lado, nos terminais periféricos esta oferta é de 28 linhas operantes, o que representa cerca de $50 \%$ da oferta na região central. Quanto ao número de ônibus ofertados em horário de pico $(07 \mathrm{~h} 30$ à $08 \mathrm{~h} 30$; e de 18h à 19h) observa-se que o recorte dos terminais centrais apresenta uma média de 195 ônibus em circulação, enquanto que o recorte periférico apresenta a média de 200 ônibus. Esse resultado poderia inferir a existência de maior número de pessoas se deslocando da periferia ao centro, o que necessita da coleta de outros dados complementares e aprofundamento para sua confirmação. Destaca-se a quantidade de ônibus ofertados no período matutino no Terminal do Boqueirão, apesar da densidade populacional ser a menor de todos os recortes analisados. Esse resultado pode denotar que o volume de usuários neste terminal não corresponda aos moradores do bairro, e evidencie um movimento pendular metropolitano, caracterizado segundo Deschamps (2004) como aquelas pessoas que se deslocam do seu lugar de residência para trabalhar e/ou estudar em outro município.

Estabelecendo um comparativo entre todos os recortes analisados, verifica-se que a área central e o Terminal do Capão Raso possuem oferta similar de ônibus que circulam nos horários de pico matutino e vespertino. Essa situação é bastante diversa no Terminal do Boqueirão, onde constata-se que a oferta de ônibus no período matutino é cerca de $55 \%$ superior em relação ao número de ônibus que circulam no mesmo terminal no período vespertino, e cerca de $41 \%$ superior à média de ônibus disponíveis nos demais recortes, no mesmo período matutino. São resultados que indicam a necessidade de maior aprofundamento. Algumas hipóteses a serem verificadas seriam: o perfil dos moradores do Boqueirão seria de trabalhadores do setor terciário - atividade típica da área central de Curitiba; a proximidade do recorte com o Município de São José dos Pinhais, o segundo município em população da Região Metropolitana de Curitiba e a segunda maior economia do Estado do Paraná (IPARDES, 2016), o que poderia influenciar nas características de deslocamento da população, não apenas em escala municipal, mas também metropolitana (Gráfico 04).

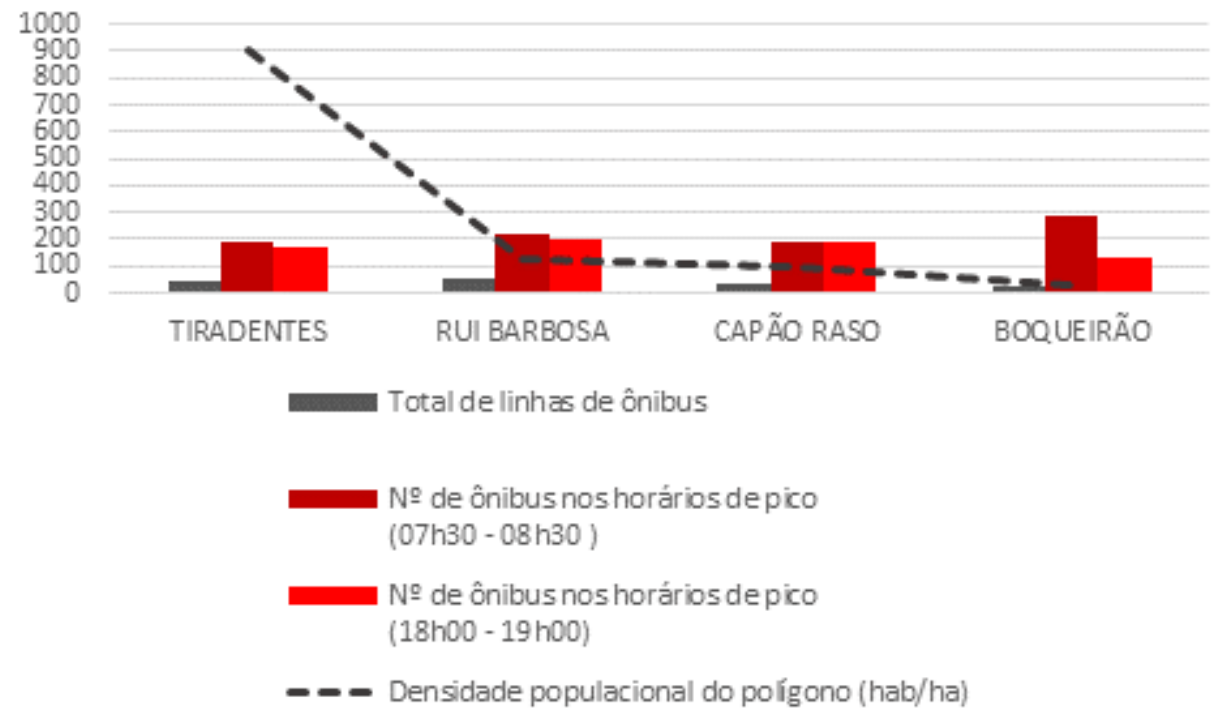

Gráfico 04: Densidade populacional e oferta de transporte coletivo por recorte espacial analisado (IBGE, 2010; URBS, 2016)

Sendo objetivo da pesquisa estabelecer comparativos entre as condições espaciais apresentadas no entorno dos terminais de ônibus do sistema BRT, foi construída uma escala de valores fundamentada no referencial teórico da pesquisa, onde se valoriza como condição espacial adequada a associação de diversidade de usos e densidade populacional em relação à oferta de transporte coletivo (ver Considerações Metodológicas). Assim, a definição dessas categorias de análise fundamentaram-se no conceito de desenvolvimento orientado do transporte público (TOD) ao considerar que a concentração de pessoas e diversidade de usos são relevantes para garantir a eficiência do sistema de transporte coletivo concentrando demanda e oferta de serviços no mesmo local. Portanto, foram definidas a categoria 1 , que se dedica a observação do zoneamento, enquanto previsão legal e planejamento, considerando como esse instrumento incentiva o não a diversidade, a observação da real diversidade de usos (categoria 2), demografia - densidade (categoria 3) e circulação de ônibus - pólo gerador de tráfego (categoria 4) como elementos a serem verificados in loco para a elaboração de análises e conclusões (Newman, 1996; Lund, Cervero, Wilson, 2004; Petersen, 2004; Jabareen, 2006; Litman, 2008). Os resultados obtidos são apresentados na Tabela 02. 


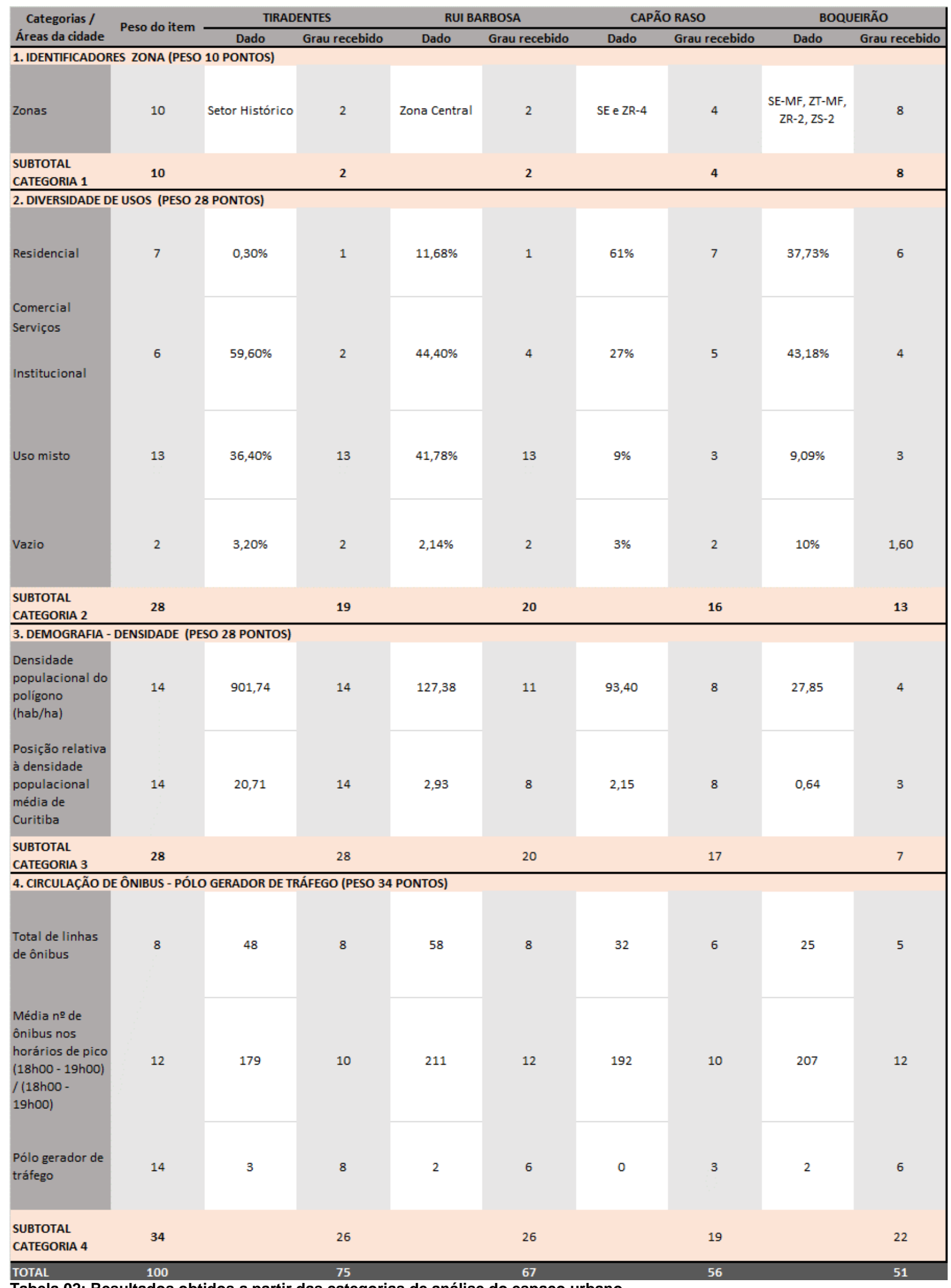

Tabela 02: Resultados obtidos a partir das categorias de análise do espaço urbano

Elaboração própria 
Conforme a Tabela 02, verifica-se que na categoria 1, no quesito zoneamento, valorizou-se mais os locais em que há zonas que admitem maior diversidade de usos o que, em tese, promoveria maior variedade de formas de ocupação do espaço, otimizando a infraestrutura, equipamentos e serviços, além de, ao mesmo tempo, propiciar menor necessidade de deslocamento, como apontam as teorias e práticas do urbanismo durável (Beatley, 2000; Masboungi, 2012; Charlot-Valdieu; Outrequin, 2011). Assim, os recortes das áreas centrais, Praças Tiradentes e Rui Barbosa, apresentaram menor valoração (2 pontos). A área periférica do Terminal do Boqueirão apresentou 8 pontos, em razão de que, a despeito da distância em relação ao Marco Zero, apresenta maior diversidade de zonas, comparativamente ao Terminal do Capão Raso (4 pontos). No entanto, ressalta-se que, especialmente a Zona Central onde se localiza o Terminal Rui Barbosa possui grande diversidade de usos e atividades que conferem dinâmica ao local, indicando que nas etapas subsequentes da pesquisa se considere a revisão da valoração desse item, com foco na variedade de atividades permitidas e não na quantidade de zonas previstas em lei.

Com relação à diversidade de usos, considerou-se que esta depende da associação do uso residencial com demais usos (comerciais, de serviços, institucionais, misto), o que segundo Jacobs (2011) contribuiria para a vitalidade do espaço, para a presença constante de pessoas circulando nas ruas. Também se considerou que a presença de vazios induz ao espraiamento da ocupação urbana, atribuindo-se maior pontuação a medida em que sua presença era reduzida no espaço. Este entendimento é baseado nas bases teóricas da cidade compacta e de maior sustentabilidade, como apontam Beatley (2000), Masboungi (2012), CharlotValdieu; Outrequin (2011). Assim, os recortes da área central apresentaram maior valoração, sendo 19 pontos para o Terminal Tiradentes e 20 pontos para o Terminal Rui Barbosa. Por sua vez, o Terminal do Capão Raso (na área periférica) apresentou significativa ocupação residencial (61\%) associada aos demais usos comercial, de serviços, institucional e misto (36\%). Assim, verifica-se que, embora o entorno do Terminal do Boqueirão apresente maior diversidade de zonas, isso não reproduz maior diversidade de usos, tendo em vista que, comparativamente ao outro terminal periférico, do Capão Raso, obteve melhor desempenho nesta categoria, somando 16 pontos.

$\mathrm{Na}$ terceira categoria, pontuaram-se os quesitos relativos à densidade populacional no polígono de análise e em relação à cidade de Curitiba. O recorte da Praça Tiradentes obteve maior valoração (28 pontos) por concentrar maior densidade populacional, conforme preconiza Nilsson et. al (2014), o que em tese, otimizaria o uso do sistema de transporte BRT. Esse resultado é consequência da concentração de edifícios de maior gabarito, com usos residenciais e mistos.

A última categoria de análise leva em conta os espaços do recorte como polos geradores de tráfego, segundo a lógica defendida por Newman e Kenworthy (2006) a respeito de que o desenho urbano pode contribuir para a redução da dependência do automóvel, visando maior viabilidade para uso dos equipamentos e também o incremento da sustentabilidade urbana. Também Beatley (2000) fundamenta esse posicionamento teórico ao defender o esverdeamento da cidade pelo menor uso de veículos. A localização de equipamentos cujo uso envolve grande circulação de pessoas e/ou veículos são considerados fatores importantes para a relação uso do solo e mobilidade e, portanto, possuem maior na avaliação nesta categoria (Lima, 2015). Como resultado, os recortes das áreas centrais também apresentaram maior valoração (26 pontos), seguido pelo Terminal do Boqueirão com 22 pontos. Aqui confirma-se também que o Boqueirão apresenta potencial de centralidade pois, apesar de possuir baixa densidade populacional, se constitui em lócus de uma grande variedade de atividades nos setores secundário e terciário da economia municipal, de alcance metropolitano.

Os resultados obtidos em todas as categorias de análise atestaram que, segundo a metodologia aplicada, a Praça Tiradentes apresenta melhores condições na relação entre desenho urbano e mobilidade, por concentrar densidade populacional e diversidade de usos em uma área atendida pelo sistema de transporte. Os dados ainda permitem verificar que o entorno do Terminal Capão Raso apresenta melhores relações entre forma urbana e mobilidade, comparativamente ao Terminal do Boqueirão, tendo em vista que ambos são terminais periféricos. Assim, verifica-se que os recortes analisados na área central apresentam características bastante similares. Tal fato, no entanto, não é observado quando se analisa os terminais nos eixos periféricos. Embora ambos estejam em vetores de significativo crescimento populacional, considerando sua conexão com os municípios vizinhos, o padrão de ocupação no entorno destes terminais é distinto.

Enquanto que no recorte espacial do Terminal do Capão Raso, situado em área periférica, observa-se a conformação de uma nova centralidade urbana, caracterizada pela alta diversidade de usos, densidade populacional, que se aproxima aos índices das áreas centrais, como a Praça Rui Barbosa, e significativa 
oferta de transporte coletivo, no entorno do Terminal do Boqueirão constata-se que, a despeito da presença deste equipamento urbano e da presença de usos diversificados, a condição de subcentro se deve a atividades não-residenciais, tendo em vista a baixa densidade populacional deste local $(27,85 \mathrm{hab} . / \mathrm{ha})$. A ocupação residencial no Boqueirão é mais espraiada, com estrutura fundiária de lotes de maiores dimensões e edificações de poucos pavimentos. Nesse sentido, verifica-se que há outros fatores que influenciam no padrão de ocupação destas áreas, embora a presença do terminal urbano e a oferta do sistema de transporte ainda seja relevante nesta conformação espacial.

\section{CONSIDERAÇÕES FINAIS}

Os resultados demonstrados partem da elaboração de uma metodologia que pretende avaliar padrões de ocupação por meio da relação entre forma urbana e espaços decorrentes de um sistema de mobilidade. Verifica-se que há necessidade de aprofundamento desta discussão, no intuito de melhor compreender a relação entre o espaço urbano e sistemas de mobilidade, bem como desenvolver a mensuração desta relação, de modo a reconhecer padrões que sejam mais sustentáveis. A metodologia bem como os resultados demonstrados servem como uma aproximação, no intuito de definir, analisar e refletir sobre indicadores que possam contribuir, de forma mais efetiva, com a determinação da influência espacial, em termos de uso e ocupação, em espaços decorrentes de sistema de mobilidade urbana.

Assim, o recorte de análise aqui proposto, embora restrito, permite a aplicação dos procedimentos metodológicos, verificando o comportamento dos indicadores de forma individual e em conjunto. Além disso, permite evidenciar que há outros fatores que influenciam a relação entre desenho urbano e sistemas de mobilidade, que aqui não estão contemplados. Evidência deste fato, é o resultado obtido a partir do comparativo entre dois terminais periféricos que apresentam contextos urbanos similares. Visando aprofundamento dessa investigação se verifica que, o desenvolvimento poderia ser realizado com base em outros procedimentos metodológicos que complementassem os já utilizados na presente etapa, como a análise multicritério, por exemplo.

Considera-se, portanto, que a presente pesquisa tem potencial de desenvolver ferramentas e indicadores que subsidiem a tomada de decisões na gestão pública quanto à relação entre a conformação de espaços urbanos no entorno de terminais, no que tange a alterações nos padrões de uso e ocupação do solo frente à oferta ou demanda do transporte coletivo, de modo a otimizar a eficiência do sistema e da ocupação dos espaços urbanos de forma mais sustentável, a partir da efetiva aplicação dos princípios de desenvolvimento orientado do transporte público.

\section{REFERÊNCIAS BIBLIOGRÁFICAS.}

ALLAIRE, J. (2006). Choisir son mode de ville: formes urbaines et transports dans les villes emergentes. Les Cahiers de global chance (Montreuil),21, 66-70.

ALTER, C.H. (1976). Evaluation of public transit services: the level of services concept. Transportation Research Board (Washington), 606, 37-40.

AMADO, M. P. (2009). Planeamento urbano sustentável.Lisboa:Casal Cambra.

ARRAIS, T. A. (2005). Mobilidade e centralidade: breves reflexões sobre a problemática metropolitana. In: MOYSÉS, A. Cidade, segregação urbana e planejamento (346-355). Goiânia: Ed. da UCG.

BEATLEY, T. (2000). Green urbanism. Learning from europeian cities. Washington: Island Press.

CAMPOS, R. F. (2005). Análise da influência da orientação da testada dos lotes na ocupação do setor estrutural de Curitiba. 217f. Dissertação. (Mestrado em Construção Civil). - Programa de PósGraduação em Construção Civil, Universidade Federal do Paraná, Curitiba.

CHARLOT-VALDIEU, C.; OUTREQUIN, P. (2011). L'urbanisme durable. Concevoir un écoquartier. Paris: Le Moniteur.

COMEC - Coordenação da Região Metropolitana de Curitiba (2006). Plano de Desenvolvimento Integrado da Região Metropolitana de Curitiba: Propostas de Ordenamento Territorial e Novo Arranjo Institucional. Curitiba: COMEC.

DEL RIO, V; SIEMBIEDA, W. (2015). Desenho Urbano Contemporâneo no Brasil. Rio de Janeiro: LTC. DEL RIO, V. (1990). Introdução ao desenho urbano no processo de planejamento. São Paulo: PINI. 
DESCHAMPS, M. V. (2004). Vulnerabilidade socioambiental da Região Metropolitana de Curitiba. $192 f$. Tese (Doutorado em Meio Ambiente e Desenvolvimento) - Universidade Federal do Paraná, Curitiba.

DUDEQUE, I. T. (2010). Nenhum dia sem uma linha: uma história do urbanismo em Curitiba. São Paulo: Studio Nobel.

FREYMAN, M. (2012). An Exploration of Sustainability and its Application to Corporate

Reporting. Cambridge: Harvad University.

FRÚGOLI JÚNIOR., H. (1995). São Paulo: espaços públicos e interação social. São Paulo: Marco Zero.

HARVEY, D.(2010). Social justice and the city. University of Georgia Press.

IBGE - Instituto Brasileiro de Geografia e Estatística (2010). Censos demográficos 2000 a 2010. Rio de Janeiro: IBGE.

IPARDES - Instituto Paranaense de Desenvolvimento Econômico e Social (2016). Cadernos Municipais. Curitiba: IPARDES.

IPPUC - Instituto de Pesquisa e Planejamento Urbano de Curitiba (2016). O planejamento urbano de Curitiba. Curitiba: IPPUC. (2004). Plano Diretor 2004: o Planejamento Urbano de Curitiba. Curitiba: IPPUC.

JABAREEN, Y. R. (2006). Sustainable urban forms: their typologies, models and concepts. Journal of Planning Education and Research (Estados Unidos), 26, 1, 38-52.

JACOBS, J. (2011). Morte e vida de grandes cidades. São Paulo: Martins Fontes

KATES, R.W., PARRIS, T.M. y LEISEROWITZ, A. (2005). What's Sustainable Development. Environment. Science and Policy for Sustainable Development, 47, 3, 8-21.

KENWORTHY,J., LAUBE, F.B. (1999). Patterns of automobile dependence in cities: an international overview of key physical and economic dimensions with some implications for urban policy. Transportation Research, 33, 691-723.

KOHLSDORF, M. E.(1996). A apreensão da forma da cidade. Brasília: UNB.

LAMAS, J. M. R. G. (2014). Morfologia urbana e Desenho da Cidade. Lisboa: Calouste Gulbenkian.

LIMA, C. de A.; FORTUNATO, R.A. (2016). Mobilidade e qualidade espacial urbana no entorno de terminais do sistema BRT de Curitiba: desenho urbano e condições socioambientais. $7^{\circ}$ Congresso Lusobrasileiro para o Planejamento Urbano, Regional, Integrado e Sustentável - PLURIS, Maceió, 5-7 outubro (impresso).

LIMA, C. de A. (2015). Configuração urbana e o sistema BRT de Curitiba - Brasil. Investigando a qualidade espacial do entorno de terminais: uma metodologia em construção. VII Seminário Internacional de Investigación en Urbanismo, Barcelona, junho (Anais eletrônicos...) Disponível em: < https://upcommons.upc.edu/handle/2117/80278>. (Consulta: 23/10/2016).

LIMA, C. de A. (2010). Ignis Mutat res: cidade, mobilidade, energia e governança. Projeto de pesquisa Departamento de Arquitetura e Urbanismo, Universidade Federal do Paraná, Curitiba.

LITMAN, T. (2008). Land use impacts on transport. Victoria: Victoria Transport Policy Institute - VTPI.

LUND, H. M.; CERVERO, R.; WILLSON, R.W. (2004). Travel characteristics of transit-focused development in California. Oakland: Bay Area Rapid Transit District and California Department of Transportarion.

MARCONI, M. de A.; LAKATOS, E. M. (2004). Metodologia científica. São Paulo: Atlas.

MASBOUNGI, A.(dir). (2012). Projets urbains durables. Paris: Le Moniteur.

NEWMAN, P; KENWORTHY, J. (2006). Urban design to reduce automobile dependence. Opolis, 2, 1, 3552.

NEWMAN, P. (1996). Reducing automobile dependence. Environment and urbanization (Londres), 8, 1, 6792.

NILSSON, K.; NIELSEN, T.S.; AALBERS, C.; BELL, S.; BOITIER, S. (2014). Strategies foi sustainable urban development and urban-rural linkages. The European Journal of Spatial Development (Delft), março 2014, 1-26.

PALOMO, P. S. (2005). La planificación verde en las ciudades. Barcelona: Gustavo Gili.

PEREIRA COSTA, S.A.; TEIXEIRA, M.C.V. (2014). The study of urban form in Brazil. Urban Morphology 18, 2, 119-27 International Seminar on Urban Form.

PETERSEN, R.(2004). Land use planning and urban transport: sustainable transport: sourcebook for policymakers in developing cities. Eschborn: Deutsche Gesellschaft fUr Technische Zusammenarbeit GTZ.

PMC - PREFEITURA MUNICIPAL DE CURITIBA (2017). Aqui o progresso anda de ônibus. Curitiba: PMC site.

POPPER, K. S. (1975). A lógica da pesquisa científica. São Paulo: Cultrix.

SALINGAROS, N. A. (1998). A teoria da teia urbana. Journal of Urban Design, 3, 53-71.

SILVEIRA, L.S. da C. (2012). Determinação de Índice da situação do transporte. 137f. Tese (Doutorado em Transportes) - Universidade de Brasília, Brasília.

URBS - URBANIZAÇÃO DE CURITIBA (2016). Rede Integrada de Transporte. Curitiba: URBS. 
VARGAS, H.C.; CASTILHO, A. L. H. de (2006). Intervenções em Centros Urbanos: objetivos, estratégias e resultados. Barueri. São Paulo: Manole.

\section{AGRADECIMENTOS AOS COLABORADORES:}

As autoras agradecem a colaboração dos estudantes voluntários do Programa de Iniciação Científica que interagem no âmbito do Projeto Ignis Mutat Res, do Grupo de Pesquisa Cidade, Meio Ambiente e Políticas Públicas - CIMAPP, do DAU/ UFPR.

Estudantes colaboradores:

a) Ano 2016: Eduardo Sinegaglia; Felipe Tibes Karvat; Letícia Midori Akita; Lissandra Baldissera; Marina Genosto Gennari e Renata de Oliveira Kuzma.

b) Ano 2015: Danilo Akio Hiraoka; Evelyn Makovski; Hermes Eduardo Nichele; Lucas Felipe Pereira Cará; Maria Gianina Leguizamón Coronel; Matheus Fernandes. 